\title{
Biochemical Factors Modulating Cellular Neurotoxicity of Methylmercury
}

\author{
Parvinder Kaur, ${ }^{1}$ Michael Aschner, ${ }^{2}$ and Tore Syversen ${ }^{3}$ \\ ${ }^{1}$ Department of Neuroscience, Norwegian University of Science and Technology, 7489 Trondheim, Norway \\ ${ }^{2}$ Departments of Pediatrics and Pharmacology and The Kennedy Center for Research on Human Development, Vanderbilt University \\ Medical Center, B-3307 Medical Center North, 1162 21st Avenue, Nashville, TN 37232-2495, USA \\ ${ }^{3}$ Department of Neuroscience, Faculty of Medicine, Norwegian University of Science and Technology, Olav Kyrres Gate 3, \\ 7489 Trondheim, Norway
}

Correspondence should be addressed to Tore Syversen, tore.syversen@ntnu.no

Received 30 April 2011; Revised 28 June 2011; Accepted 13 July 2011

Academic Editor: Shelley Bhattacharya

Copyright () 2011 Parvinder Kaur et al. This is an open access article distributed under the Creative Commons Attribution License, which permits unrestricted use, distribution, and reproduction in any medium, provided the original work is properly cited.

\begin{abstract}
Methylmercury $(\mathrm{MeHg})$, an environmental toxicant primarily found in fish and seafood, poses a dilemma to both consumers and regulatory authorities, given the nutritional benefits of fish consumption versus the possible adverse neurological damage. Several studies have shown that MeHg toxicity is influenced by a number of biochemical factors, such as glutathione (GSH), fatty acids, vitamins, and essential elements, but the cellular mechanisms underlying these complex interactions have not yet been fully elucidated. The objective of this paper is to outline the cellular response to dietary nutrients, as well as to describe the neurotoxic exposures to MeHg. In order to determine the cellular mechanism(s) of toxicity, the effect of pretreatment with biochemical factors (e.g., N-acetyl cysteine, (NAC); diethyl maleate, (DEM); docosahexaenoic acid, (DHA); selenomethionine, SeM; Trolox) and $\mathrm{MeHg}$ treatment on intercellular antioxidant status, $\mathrm{MeHg}$ content, and other endpoints was evaluated. This paper emphasizes that the protection against oxidative stress offered by these biochemical factors is among one of the major mechanisms responsible for conferring neuroprotection. It is therefore critical to ascertain the cellular mechanisms associated with various dietary nutrients as well as to determine the potential effects of neurotoxic exposures for accurately assessing the risks and benefits associated with fish consumption.
\end{abstract}

\section{Introduction}

Methylmercury ( $\mathrm{MeHg}$ ) is a ubiquitous environmental toxicant [1]. Several catastrophic epidemics resulting from the consumption of food contaminated by $\mathrm{MeHg}$ have highlighted the potentially disastrous effects of $\mathrm{MeHg}$ on living organisms. Important examples include outbreaks in Minamata [2], Niigata [3], and Iraq [4]. MeHg is a potent neurotoxicant which affects both the developing and mature CNS $[5,6]$. In infants, MeHg causes widespread and diffuse damage, whereas focal damage is caused in the adult brain. In adults, chronic $\mathrm{MeHg}$ poisoning results in the degeneration of the sensory cerebral cortex and the cerebellum, thereby leading to severe neurological disturbances, such as cerebellar ataxia and paresthesia, sensory and speech impairment, and the constriction of the visual field $[4,7,8]$. The patho- logical changes involve general neuronal degeneration with gliosis in the calcarine, and precentral and postcentral areas of the cerebral cortex, as well as the loss of granular cells in the cerebellar cortex [9]. In biological systems, MeHg exists only at a very low concentration as a free, unbound cation [10] which can bind to sulfhydryl groups (-SH) of amino acids with a very high affinity ( $\log \mathrm{K}$ in the order of 15 23) [10]. This affinity of $\mathrm{Hg}$ for sulphur and - $\mathrm{SH}$ groups is a major factor underlying the biochemical properties of $\mathrm{MeHg}$, which, consequently, leads to its interference with the enzyme activities of several cellular targets.

In the marine ecosphere, $\mathrm{MeHg}$ is sustained $[11,12]$ and, after bioaccumulation, is introduced into the human population through the dietary intake of fish and seafood products. [13-15]. MeHg toxicity due to the consumption of adulterated fish represents a major public health issue. Greater 
fish consumption in many cases is paralleled by increased $\mathrm{MeHg}$ intake [16]; however, conversely, lower maternal seafood intake has also been associated with higher risk for a suboptimal developmental outcome [17]. According to the Avon Longitudinal Study of Parents and Children (ALSPAC), the authors reported that maternal seafood intake during pregnancy of less than $340 \mathrm{~g}$ per week was associated with an increased likelihood for their children to fall into the lowest quartile for verbal intelligence quotient (IQ) when compared with mothers who consumed more than $340 \mathrm{~g}$ of seafood per week. Though $\mathrm{Hg}$ consumption was not assessed in this study, it is reasonable to assume that greater fish consumption was paralleled by increased $\mathrm{MeHg}$ intake. Moreover, several discrepancies in health outcomes in fish-eating populations have been reported, such as neurodevelopmental impairments in New Zealand [18-20] and the Faroe Islands $[21,22]$, as opposed to the beneficial effects noted in Canada [23], the Seychelles [24, 25], Peru [26], and the United States [17, 27-30]. Additionally, laboratory studies have also shown that dietary factors, such as selenium, cysteine, protein, fat, fiber, and vitamin contents can modulate the toxicity and excretion of mercury $[31,32]$. A previous study [33] has also shown a significantly higher rate of fecal excretion as well as a lower degree of $\mathrm{MeHg}$ accumulation in the brains of rats fed naturally contaminated fish as compared to rats fed fish containing chemically added $\mathrm{MeHg}$. The above-mentioned studies indicate that, in addition to intrinsic, genetic factors, the phenotypic responses to $\mathrm{MeHg}$ exposure may ultimately depend on a number of complex interactions within biological systems involving both mercury and various dietary factors. It is therefore important to study the effect(s) of confounding dietary factors that occur when fish is consumed on $\mathrm{MeHg}$ distribution and neurotoxicity. In this respect, it must be noted that different types of fish accumulate different concentrations of nutrients and contaminants [34-36]. Therefore it is of considerable interest to determine how each component acts individually (as well as with others) and influences the potential risk from $\mathrm{MeHg}$ exposure. These cellular and molecular mechanisms of $\mathrm{MeHg}$ action, as well as the underlying processes of its interaction with dietary components have yet to be defined, especially in specific central nervous system (CNS) targets. Accordingly, this paper focuses on studies directed toward estimating the effect(s) of dietary modifiers on MeHg neurotoxicity, potentially providing information about critical cellular mechanisms responsible for conferring neuroprotection from a diet that includes $\mathrm{MeHg}$-contaminated fish.

\section{MeHg-Induced Oxidative Effects: Reactive Oxygen Species (ROS) Generation and Glutathione (GSH) Depletion}

The disruption of redox cellular homeostasis by an excess of ROS formation, which leads to cumulative oxidative stress appears to play a key role in the in vivo pathological process of $\mathrm{MeHg}$ intoxication [37-42]. Conversely, several studies have demonstrated the partial amelioration of $\mathrm{MeHg}$ toxicity in the presence of antioxidants by the inhibition of
ROS generation $[40,43,44]$. Although the critical role of oxidative stress in the pathogenesis of $\mathrm{MeHg}$ cytotoxicity has been clarified, the molecular mechanisms underlying MeHgmediated oxidative stress have not yet been fully elucidated. A major source of $\mathrm{MeHg}$-induced increases in ROS generation may be the mitochondrial electron transport chain. The damaged mitochondrion increases oxidative stress, leading to a decrease in defense mechanisms, such as reduced GSH content, which represents one of the principal endogenous antioxidants. In addition, binding to GSH is reported to be responsible for the excretion of $\mathrm{MeHg}$. Therefore, decreased GSH levels usually parallel increased oxidative stress due to $\mathrm{MeHg}$ exposure [45-49]. However, two epidemiological studies associating oxidative stress and $\mathrm{MeHg}$ exposure [50, 51] have shown both an increase and a decrease in GSH levels with increased total $\mathrm{Hg}$ levels. This suggests that $\mathrm{MeHg}$ can increase ROS which may either inhibit GSH levels or initiate an adaptive response to oxidative stress by increasing GSH levels. Moreover, studies of human populations, although of direct interest, cannot be controlled for multiple confounding variables. This obstacle can be overcome by conducting studies on laboratory animals; such investigations can identify the mechanisms of action by which neurotoxicants and neuroprotectants interact.

\section{Role of GSH Modulators on MeHg-Induced Neurotoxicity}

Upregulation [52], or the induction of an increased synthesis of GSH [45], has been reported to provide neuroprotection against MeHg-induced neurotoxicity. A similar alleviation in $\mathrm{MeHg}$-induced cytotoxicity and oxidative stress has been reported with $\mathrm{N}$-acetyl cysteine (NAC) supplementation [39, 53-55]. The mechanisms involved in protection afforded by NAC include increased intracellular GSH [54,55] as well as a transient increase in the urinary excretion of $\mathrm{MeHg}$, which was shown to cause a decrease in the level of $\mathrm{MeHg}$ in both the adult brain and the fetus $[53,56]$. In addition, the increased amount of GSH in cortical, as compared to cerebellar, astrocytes has been reported to account for the increased $\mathrm{MeHg}$-induced ROS production in cerebellar astrocytes [55].

Conversely, the depletion of intracellular GSH with diethyl maleate (DEM) has been reported to increase cellassociated $\mathrm{MeHg}$ and $\mathrm{MeHg}$-induced $\mathrm{ROS}[48,54,55]$. The underlying mechanism of this process involves the conjugation of free sulfhydryl groups of GSH with DEM, which results in the distinct depletion of GSH. Also, gestational exposure to $\mathrm{MeHg}$ has been reported to cause the dosedependent inhibition of cerebral GSH levels, an outcome which could be correlated with increased lipid peroxidation in the pup brain [57]. These biochemical alterations were found to endure even after $\mathrm{Hg}$ tissue levels decreased, thus indicating permanent functional deficits observed after prenatal $\mathrm{MeHg}$ exposure as well as an additional molecular mechanism by which $\mathrm{MeHg}$ induces prooxidative damage in the developing CNS.

In summary, changes in intracellular $\mathrm{MeHg}$ content with GSH modulation provide an explanation for the increased 
susceptibility of certain cell types towards MeHg-induced oxidative stress $[54,55]$.

\section{Role of DHA in Modulating MeHg-Induced Neurotoxicity}

DHA cis-4,7,10,13,16,19-docosahexaenoic acid, is one of the most abundant polyunsaturated fatty acids (PUFA) in the phospholipid fractions of the mammalian brain $[58,59]$. Both seafood and breast milk serve as major dietary routes of $\mathrm{MeHg}[60,61]$ and DHA [62-65]. The ability of DHA to affect ROS is controversial, as several contrasting studies have documented the ability of DHA to decrease the level of lipid peroxide [66-68] and to cause free-radical-mediated peroxidation in the brain [69-71]. DHA have been reported to modulate $\mathrm{MeHg}$ toxicity [33, 72-74]. These studies have demonstrated the beneficial effects of DHA on using a DHAenriched diet against MeHg-induced decreases in serum albumin levels, changes in mitochondrial membrane potential, and developmental defects. However, other contradictory studies have reported no protection against $\mathrm{MeHg}$ induced behavioral defects $[75,76]$. It is therefore important to identify the biochemical mechanisms involved in the DHA protection against $\mathrm{MeHg}$ neurotoxicity.

Kaur and colleagues $[77,78]$ demonstrated that pretreatment with DHA was associated with reduced cell-associated $\mathrm{MeHg}$ in neuronal cell lines and primary cells. In addition, decreased ROS and unchanged GSH levels were found in primary cultures, whereas increased ROS and GSH depletion were found in C6 cells $[77,78]$. These differences with respect to the effect of DHA on oxidative stress could be due to the fact that the growth of cancerous cells is inhibited by DHA as compared to noncancerous cell types [71, 79]. Indeed, another recent study has shown that fish oil offers significant DNA protection as well as anti-inflammatory effects in the absence of changes in GSH levels [50]. These observations strongly suggest that DHA may neuroprotect against $\mathrm{MeHg}$ induced ROS generation even in the absence of significant changes in GSH levels.

\section{Role of Selenomethionine in Modulating MeHg-Induced Neurotoxicity}

Selenium (Se) is an essential trace element known to accumulate in significant amounts in numerous species of seafood $[80,81]$. The majority of Se in fish is in the organic form, selenomethionine (SeM) $[82,83]$, and is more bioavailable than are inorganic forms [84]. Selenium has also been detected in human milk [85]. The modulating effect of Se on $\mathrm{MeHg}$ toxicity was discovered when researchers observed that marine mammals could accumulate exceptionally high concentrations of $\mathrm{Hg}$ and Se compounds without displaying obvious symptoms of intoxication $[86,87]$. Several subsequent studies later confirmed that the toxic effects of both organic and inorganic $\mathrm{Hg}$ were prevented by Se compounds [88-92]. Treatment with different Se compounds has been shown to effectively protect cells against different toxic effects induced by $\mathrm{MeHg}$ exposure, such as cytotoxicity, fetotoxicity, neurotoxicity, and developmental and neurobehavioral toxicity [93-97]. In addition, Se deficiency has been shown to potentiate the adverse effects of $\mathrm{MeHg}$ toxicity in rodents $[98,99]$.

With regard to epidemiological studies and Se content, it is important to note that Faroe Islanders, by virtue of a whale meat diet, are generally exposed to $\mathrm{MeHg}$ levels that are in excess of Se levels [100], whereas the Seychellois are largely ocean fish consumers, and Se molar concentrations tend to greatly exceed $\mathrm{MeHg}$ concentrations in this seafood source [101]. In addition, the dietary Se status in the New Zealand population was extremely poor at the time of the study [102]. This distinction could be one explanation for the different effects noted in these studies, although additional evidence is needed to support this hypothesis [103]. Therefore, developing a better understanding of the mechanisms associated with the interaction of $\mathrm{MeHg}$ and Se is of particular necessity.

Several studies have indicated that the mechanism underlying Se's ability to ameliorate $\mathrm{MeHg}$ toxicity is related to an antioxidant effect [104-108], which includes the formation of GSH [109], higher glutathione peroxidase (GPx) activity [85], increased selenoprotein levels [110-112], and the reduction of organic hydroperoxides [113-115]. Additionally, studies have shown that binding of $\mathrm{MeHg}[116$, 117] and the formation of a highly stable organic MeHgselenocysteine complex [98] also influence the accumulation of $\mathrm{MeHg}$ in tissues [118-121] and the uptake of $\mathrm{MeHg}$ in cells $[114,122-124]$. Furthermore, Se is known to enhance the excretion of $\mathrm{MeHg}[56,125]$, and a recent study has shown [126] that SeM can demethylate MeHg under physiologically and environmentally relevant conditions. Hence, the interactive effects between $\mathrm{MeHg}$ and SeM result in reduced cellassociated $\mathrm{MeHg}$ and prooxidant response from $\mathrm{MeHg}$.

\section{Role of Trolox in Modulating MeHg-Induced Neurotoxicity}

Seafood serves as a source of vitamins, with estimates ranging between 4.84 and $17.90 \mu \mathrm{g}$ vitamin $\mathrm{E}$ per gm of fish [127], which makes this vitamin the most significant physiologic membrane-associated antioxidant available from seafood. Trolox (6-hydroxy-2,5,7,8-tetramethylchroman-2carboxylic acid), a water soluble analog of vitamin E [128], serves as a better antioxidant than vitamin $\mathrm{E}[129,130]$ due to its improved access to the hydrophilic compartments of the cells [131], as well as its stoichiometric properties [132]. Trolox scavenges free radicals [59, 133-137] via the $\mathrm{H}$-donating groups $[128,138]$. Treatment with Trolox has been reported to protect against MeHg-induced cytotoxicity [139], the decrease in mitochondrial electron transport system enzyme activities, and the increase of mRNAs of antioxidant enzymes $[108,140]$. Trolox treatment has also been shown to reverse ROS induction by $\mathrm{MeHg}$ in primary astrocyte cultures [44] and to prevent MeHg-induced oxidative stress [141], where the modulating effect of Trolox on cellular ROS levels was not accompanied by changes in cellular MeHg, GSH, or MTT activity [141]. These findings indicate that Trolox affords protection against ROS by 
the direct quenching of free radicals and not by $\mathrm{MeHg}$ chelation or by the induction of increased levels of GSH or mitochondrial enzymes. In fact, it has been previously shown that in vivo protection with Trolox does not affect intracellular GSH [142, 143] or MeHg levels [140]. The recognition of the protective effects of Trolox and the identification of its mechanisms via in vitro models establish that vitamindependent antioxidant defences are important factors in specific cells for attenuating the neurotoxic effects of a $\mathrm{MeHg}$-contaminated fish diet.

\section{Discussion}

Fish is not only an excellent nutritional source of protein, vitamins, zinc, and other minerals, but it is also a source of exposure to $\mathrm{MeHg}[144,145]$. One of the leading controversies in the $\mathrm{MeHg}$ literature originates from advisories concerning the consumption of fish [146] and from uncertainties in documentation from various regulatory agencies regarding the effects of $\mathrm{MeHg}$. The Joint FAO/WHO Expert Committee on Food Additives reported in 1978 that "the fetus may be more susceptible to $\mathrm{MeHg}$ toxicity than the adult" [147]. The United States White House in 1998 convened an international workshop where a variety of possible uncertainties and confounders important to $\mathrm{MeHg}$ toxicity evaluation were discussed. Their conclusions stated, "Even when dietary stresses and co-exposures to other chemicals could plausibly enhance or alter risk, it was still deemed that there are inadequate data on this subject to draw meaningful conclusions at this time" [148]. Later, in 2000, the National Academy of Sciences committee reported that, "60,000 children in the United States were at risk as a result of prenatal exposure" [149]. However, no justification or explanation for that conclusion was provided $[16,150]$. The issue that poses a significant dilemma for both consumers and regulatory authorities is whether fish consumption should be encouraged for its nutritional benefits to the developing brain or, conversely, whether fish consumption should be discouraged due to the possible adverse effects of MeHg on the developing CNS. This nutrition versus neurotoxicity controversy can be addressed by estimating the effects of dietary factors on MeHg-induced toxicity as well as by determining the mechanisms behind such effects. A thorough assessment of coexposure from dietary nutrients as well as neurotoxic exposures would offer valuable information for accurately determining the risks and benefits of fish consumption [151, $152]$.

This paper explores the mechanisms associated with $\mathrm{MeHg}$ and dietary nutrients obtained from the consumption of seafood. The toxicity of $\mathrm{MeHg}$ has been reported to be caused by a reduction in the amount of intracellular GSH $[45,46,48]$, which leads to the augmentation of ROS formation [37, 40-44, 153]. This paper investigates the effects of $\mathrm{MeHg}$ on oxidative stress and details the role played by GSH in modifying these effects. It also identifies the biochemical mechanisms underlying exposure to GSH, DHA, Se, Trolox, and MeHg, where these modifiers have been shown to effectively decrease $\mathrm{MeHg}$-induced ROS

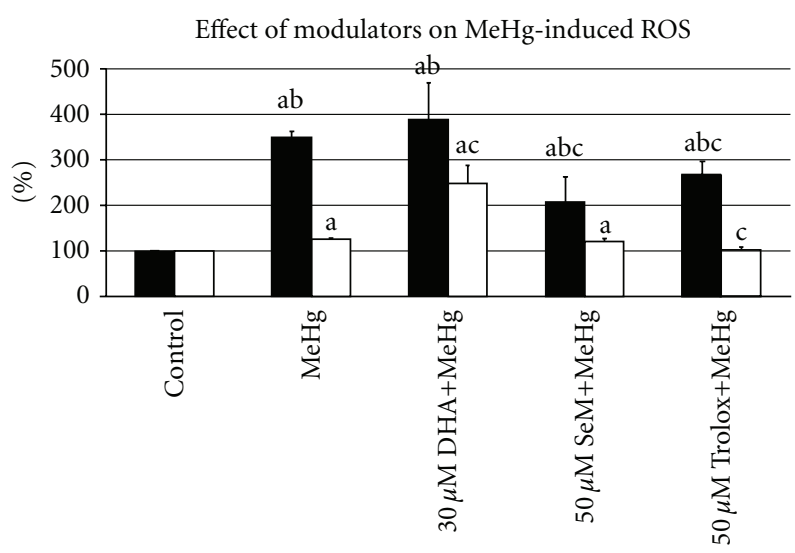

- C6 glial cell line

$\square$ B35 neuronal cell line

Figure 1: Effect of different modulators on MeHg-induced cellular ROS in C6-glial and B35-neuronal cell lines. Results are expressed as mean \pm standard deviation ( $n=8$ replicates for each cell type in two independent experiments). Superscript (a) indicates $P<0.05$ for control versus each type of treatment; (b) indicates $P<0.05$ for C6 versus B35 cell line for each type of treatment; (c) indicates $\mathrm{MeHg}$ versus DHA/SeM or Trolox+MeHg-treated group. Values represented the percentage of activity relative to control cells.

(Figure 1). In addition, it is important to note that the interaction between these dietary nutrients may have an effect on overall toxicity. For example, the benefits from Se against $\mathrm{MeHg}$ toxicity can be influenced by the intake of long-chain, polyunsaturated fatty acids (LCPUFAs) [65, 154]. It has also been shown that the shape of the doseeffect curve for $\mathrm{Hg}$ is dependent upon the co-exposure of dietary components such as Se and vitamin E [145]. This paper, concludes that GSH, DHA, Se and Trolox are strong confounders in the association of MeHg toxicity and that the interaction between them may affect the cellular oxidative status. Thus, it is necessary to consider different confounders and the various mechanisms by which they interact with $\mathrm{Hg}$ when investigating the potential beneficial effects of fish consumption. Indeed, doing so would provide valuable insight for developing a better understanding of the benefits and risks of fish consumption, acknowledging both the proven beneficial nutrients as well as the potentially dangerous contaminants contained in this important food source. Furthermore, such information would also assist public health authorities as they seek to advise the populace and as they undertake efforts to formulate appropriate dietary recommendations for consumers of fish and seafood products.

\section{Acknowledgments}

The authors gratefully acknowledge the assistance of Bente Urfjell, Lars Evje, Sunniva Hoel, and Ingrid Heggland (NTNU, Norway). M. Aschner was supported by NIEHS (Grant no. R01 07331). 


\section{References}

[1] T. W. Clarkson, "The three modern faces of mercury," Environmental Health Perspectives, vol. 110, no. 1, pp. 11-23, 2002.

[2] A. Igata, "Epidemiological and clinical features of Minamata disease," Environmental Research, vol. 63, no. 1, pp. 157-169, 1993.

[3] T. Tsubaki, T. Sato, K. Kondo et al., "Outbreak of intoxication by organic compounds in Niigata Prefecture. An epidemiological and clinical study," Japanese Journal of Medical Science \& Biology, vol. 6, pp. 132-133, 1967.

[4] F. Bakir, S. F. Damluji, I. Amin-Zaki et al., "Methylmercury poisoning in Iraq," Science, vol. 181, no. 96, pp. 230-241, 1973.

[5] W. D. Atchison, "Is chemical neurotransmission altered specifically during methylmercury-induced cerebellar dysfunction?" Trends in Pharmacological Sciences, vol. 26, no. 11, pp. 549-557, 2005.

[6] T. W. Clarkson, J. B. Hursh, P. R. Sager, and J. P. Syversen, "Biological monitoring of toxic metals," in Mercury, T. W. Clarkson, L. Friberg, G. F. Nordberg, and P. R. Sager, Eds., pp. 199-246, Plenum, New York, NY, USA, 1988.

[7] S. B. Elhassani, "The many faces of methylmercury poisoning," Journal of Toxicology-Clinical Toxicology, vol. 19, no. 8, pp. 875-906, 1982.

[8] M. Harada, "Minamata disease: methylmercury poisoning in Japan caused by environmental pollution," Critical Reviews in Toxicology, vol. 25, no. 1, pp. 1-24, 1995.

[9] D. Hunter and D. S. Russell, "Focal cerebellar and cerebellar atrophy in a human subject due to organic mercury compounds," Journal of Neurology, Neurosurgery \& Psychiatry, vol. 17, no. 4, pp. 235-241, 1954.

[10] W. L. Hughes, "A physicochemical rationale for the biological activity of mercury and its compounds," Annals of the New York Academy of Sciences, vol. 65, no. 5, pp. 454-460, 1957.

[11] P. M. Stokes and C. D. Wren, "Bioaccumulation of mercury by aquatic biota in hydroelectric reservoirs: a review and consideration of mechanisms," in Lead, Mercury, and Arsenic in the Environment, T. C. Hutchinson and K. M. Meema, Eds., pp. 255-278, John Wiley \& Sons, New York, NY, USA, 1987.

[12] M. M. Velga, J. A. Meech, and N. Onate, "Mercury pollution from deforestation," Nature, vol. 368, pp. 816-817, 1994.

[13] T. W. Clarkson, "The toxicology of mercury," Critical Reviews in Clinical Laboratory Sciences, vol. 34, no. 4, pp. 369-403, 1997.

[14] L. R. Kamps, R. Carr, and H. Miller, "Total mercurymonomethylmercury content of several species of fish," Bulletin of Environmental Contamination and Toxicology, vol. 8, no. 5, pp. 273-279, 1972.

[15] D. J. Spry and J. G. Wiener, "Metal bioavailability and toxicity to fish in low alkalinity lakes: a critical review," Environmental Pollution, vol. 71, no. 2-4, pp. 243-304, 1991.

[16] T. W. Clarkson and J. J. Strain, "Nutritional factors may modify the toxic action of methyl mercury in fish-eating populations," The Journal of Nutrition, vol. 133, no. 5, pp. 1539S1543S, 2003.

[17] J. R. Hibbeln, J. M. Davis, C. Steer et al., "Maternal seafood consumption in pregnancy and neurodevelopmental outcomes in childhood (ALSPAC study): an observational cohort study," The Lancet, vol. 369, no. 9561, pp. 578-585, 2007.

[18] K. S. Crump, T. Kjellstrom, A. M. Shipp, A. Silvers, and A. Stewart, "Influence of prenatal mercury exposure upon scho- lastic and psychological test performance: benchmark analysis of a New Zealand cohort," Risk Analysis, vol. 18, no. 6, pp. 701-713, 1998.

[19] T. Kjellstrom, P. Kennedy, S. Wallis, and C. Mantell, "Physical and mental development of children with prenatal exposure to mercury from fish. Stage I: preliminary tests at age 4," Tech. Rep., National Swedish Environmental Protection Board Report, Solna, Sweden, 1986.

[20] T. Kjellstrom, P. Kennedy, S. Wallis et al., "Physical and mental development of children with prenatal exposure to mercury from fish. Stage II: interviews and psychological tests at age 6," Tech. Rep. 3642, National Swedish Environmental Protection Board Report, Solna, Sweden, 1989.

[21] P. Grandjean, P. Weihe, R. F. White et al., "Cognitive deficit in 7-year-old children with prenatal exposure to methylmercury," Neurotoxicology and Teratology, vol. 19, no. 6, pp. 417428, 1997.

[22] P. Grandjean, P. Weihe, R. F. White, and F. Debes, "Cognitive performance of children prenatally exposed to "safe" levels of methylmercury," Environmental Research, vol. 77, no. 2, pp. 165-172, 1998.

[23] G. E. McKeown Eyssen, J. Ruedy, and A. Neims, "Methyl mercury exposure in northern Quebec. II. Neurologic findings in children," American Journal of Epidemiology, vol. 118, no. 4, pp. 470-479, 1983.

[24] P. W. Davidson, G. J. Myers, C. Cox et al., "Effects of prenatal and postnatal methylmercury exposure from fish consumption on neurodevelopment: outcomes at 66 months of age in the Seychelles child development study," Journal of the American Medical Association, vol. 280, no. 8, pp. 701-707, 1998.

[25] G. J. Myers, P. W. Davidson, C. F. Shamlaye et al., "Effects of prenatal methylmercury exposure from a high fish diet on developmental milestones in the seychelles child development study," NeuroToxicology, vol. 18, no. 3, pp. 819-830, 1997.

[26] D. O. Marsh, M. D. Turner, J. C. Smith, P. Allen, and N. Richdale, "Fetal methylmercury study in a Peruvian fisheating population," NeuroToxicology, vol. 16, no. 4, pp. 717726, 1995.

[27] S. A. Lederman, R. L. Jones, K. L. Caldwell et al., "Relation between cord blood mercury levels and early child development in a World Trade Center cohort," Environmental Health Perspectives, vol. 116, no. 8, pp. 1085-1091, 2008.

[28] D. Mozaffarian and E. B. Rimm, "Fish intake, contaminants, and human health: evaluating the risks and the benefits," Journal of the American Medical Association, vol. 296, no. 15, pp. 1885-1899, 2006.

[29] E. Oken, R. O. Wright, K. P. Kleinman et al., "Maternal fish consumption, hair mercury, and infant cognition in a U.S. Cohort," Environmental Health Perspectives, vol. 113, no. 10, pp. 1376-1380, 2005.

[30] E. Oken, M. L. Østerdal, M. W. Gillman et al., "Associations of maternal fish intake during pregnancy and breastfeeding duration with attainment of developmental milestones in early childhood: a study from the danish national birth cohort," American Journal of Clinical Nutrition, vol. 88, no. 3, pp. 789-796, 2008.

[31] L. Chapman and H. M. Chan, "The influence of nutrition on methyl mercury intoxication," Environmental Health Perspectives, vol. 108, no. 1, pp. 29-56, 2000.

[32] T. D. Landry, R. A. Doherty, and A. H. Gates, "Effects of three diets on mercury excretion after methylmercury 
administration," Bulletin of Environmental Contamination and Toxicology, vol. 22, no. 1, pp. 151-158, 1979.

[33] M. H. G. Berntssen, K. Hylland, A. K. Lundebye, and K. Julshamn, "Higher faecal excretion and lower tissue accumulation of mercury in wistar rats from contaminated fish than from methylmercury chloride added to fish," Food and Chemical Toxicology, vol. 42, no. 8, pp. 1359-1366, 2004.

[34] C. J. Bates, A. Prentice, M. C. Birch, and H. T. Delves, "Dependence of blood indices of selenium and mercury on estimated fish intake in a national survey of British adults," Public Health Nutrition, vol. 10, no. 5, pp. 508-517, 2007.

[35] J. L. Domingo, A. Bocio, G. Falco, and J. M. Llobet, "Benefits and risks of fish consumption. Part I. A quantitative analysis of the intake of omega- 3 fatty acids and chemical contaminants," Toxicology, vol. 230, no. 2-3, pp. 219-226, 2007.

[36] D. Shao, P. Liang, Y. Kang et al., "Mercury species of sediment and fish in freshwater fish ponds around the Pearl River Delta, PR China: human health risk assessment," Chemosphere, vol. 83, no. 4, pp. 443-448, 2011.

[37] S. F. Ali, C. P. LeBel, and S. C. Bondy, "Reactive oxygen species formation as a biomarker of methylmercury and trimethyltin neurotoxicity," NeuroToxicology, vol. 13, no. 3, pp. 637-648, 1992.

[38] C. F. Huang, C. J. Hsu, S. H. Liu, and S. Y. Lin-Shiau, "Ototoxicity induced by cinnabar (a naturally occurring $\mathrm{HgS}$ ) in mice through oxidative stress and down-regulated $\mathrm{Na}^{+} / \mathrm{K}^{+}$-ATPase activities," NeuroToxicology, vol. 29, no. 3, pp. 386-396, 2008.

[39] D. Petroni, J. Tsai, K. Agrawal, D. Mondal, and W. George, "Low-dose methylmercury-induced oxidative stress, cytotoxicity, and tau-hyperphosphorylation in human neuroblastoma (SH-SY5Y) cells," Environmental Toxicology. In press.

[40] C. Sanfeliu, J. Sebastia, and S. U. Ki, "Methylmercury neurotoxicity in cultures of human neurons, astrocytes, neuroblastoma cells," NeuroToxicology, vol. 22, no. 3, pp. 317327, 2001.

[41] T. A. Sarafian, "Methylmercury-induced generation of free radicals: biological implications," Metal Ions in Biological Systems, vol. 36, pp. 415-444, 1999.

[42] S. Yee and B. H. Choi, "Oxidative stress in neurotoxic effects of methylmercury poisoning," NeuroToxicology, vol. 17, no. 1, pp. 17-26, 1996.

[43] S. Gasso, R. M. Cristofol, G. Selema et al., "Antioxidant compounds and $\mathrm{Ca}^{(2+)}$ pathway blockers differentially protect against methylmercury and mercuric chloride neurotoxicity," Journal of Neuroscience Research, vol. 66, no. 1, pp. 135-145, 2001.

[44] G. Shanker and M. Aschner, "Methylmercury-induced reactive oxygen species formation in neonatal cerebral astrocytic cultures is attenuated by antioxidants," Molecular Brain Research, vol. 110, no. 1, pp. 85-91, 2003.

[45] B. H. Choi, S. Yee, and M. Robles, "The effects of glutathione glycoside in methyl mercury poisoning," Toxicology and Applied Pharmacology, vol. 141, no. 2, pp. 357-364, 1996.

[46] K. Miura and T. W. Clarkson, "Reduced methylmercury accumulation in a methylmercury-resistant rat pheochromocytoma PC12 cell line," Toxicology and Applied Pharmacology, vol. 118, no. 1, pp. 39-45, 1993.

[47] T. Sarafian and M. A. Verity, "Oxidative mechanisms underlying methyl mercury neurotoxicity," International Journal of Developmental Neuroscience, vol. 9, no. 2, pp. 147-153, 1991.

[48] T. A. Sarafian, L. Vartavarian, D. J. Kane, D. E. Bredesen, and M. A. Verity, "bcl-2 expression decreases methyl mercury- induced free-radical generation and cell killing in a neural cell line," Toxicology Letters, vol. 74, no. 2, pp. 149-155, 1994.

[49] K. Vijayalakshmi and P. P. Sood, "Ameliorative capacities of vitamins and monothiols post therapy in the restoration of methylmercury altered glutathione metabolism," Cellular and Molecular Biology, vol. 40, no. 2, pp. 211-224, 1994.

[50] D. Grotto, J. Vicentini, J. P. Friedmann Angeli et al., "Evaluation of protective effects of fish oil against oxidative damage in rats exposed to methylmercury," Ecotoxicology and Environmental Safety, vol. 74, no. 3, pp. 487-493, 2011.

[51] M. C. Pinheiro, B. M. Macchi, J. L. Vieira et al., "Mercury exposure and antioxidant defenses in women: a comparative study in the Amazon," Environmental Research, vol. 107, no. 1, pp. 53-59, 2008.

[52] S. Li, S. A. Thompson, J. S. Woods et al., "Localization of $\gamma$-glutamylcysteine synthetase mRNA expression in mouse brain following methylmercury treatment using reverse transcription in situ PCR amplification," Toxicology and Applied Pharmacology, vol. 140, no. 1, pp. 180-187, 1996.

[53] S. Amonpatumrat, H. Sakurai, P. Wiriyasermkul, and N. Khunweeraphong, "L-glutamate enhances methylmercury toxicity by synergistically increasing oxidative stress," Journal of Pharmacological Sciences, vol. 108, no. 3, pp. 280-289, 2008.

[54] P. Kaur, M. Aschner, and T. Syversen, "Glutathione modulation influences methyl mercury induced neurotoxicity in primary cell cultures of neurons and astrocytes," NeuroToxicology, vol. 27, no. 4, pp. 492-500, 2006.

[55] P. Kaur, M. Aschner, and T. Syversen, "Role of glutathione in determining the differential sensitivity between the cortical and cerebellar regions towards mercury-induced oxidative stress," Toxicology, vol. 230, no. 2-3, pp. 164-177, 2007.

[56] D. A. Aremu, M. S. Madejczyk, and N. Ballatori, "N-acetylcysteine as a potential antidote and biomonitoring agent of methylmercury exposure," Environmental Health Perspectives, vol. 116, no. 1, pp. 26-31, 2008.

[57] J. Stringari, A. K. Nunes, J. L. Franco et al., "Prenatal methylmercury exposure hampers glutathione antioxidant system ontogenesis and causes long-lasting oxidative stress in the mouse brain," Toxicology and Applied Pharmacology, vol. 227, no. 1, pp. 147-154, 2008.

[58] G. H. Lopez, M. G. Ilincheta de Boschero, P. I. Castagnet, and N. M. Giusto, "Age-associated changes in the content and fatty acid composition of brain glycerophospholipids," Comparative Biochemistry and Physiology, vol. 112, no. 2, pp. 331-343, 1995.

[59] M. Okada, T. Amamoto, M. Tomonaga et al., "The chronic administration of docosahexaenoic acid reduces the spatial cognitive deficit following transient forebrain ischemia in rats," Neuroscience, vol. 71, no. 1, pp. 17-25, 1996.

[60] J. L. Franco, A. Teixeira, F. C. Meotti et al., "Cerebellar thiol status and motor deficit after lactational exposure to methylmercury," Environmental Research, vol. 102, no. 1, pp. 22-28, 2006.

[61] C. B. Manfroi, F. D. Schwalm, V. Cereser et al., "Maternal milk as methylmercury source for suckling mice: neurotoxic effects involved with the cerebellar glutamatergic system," Toxicological Sciences, vol. 81, no. 1, pp. 172-178, 2004.

[62] E. Larque, H. Demmelmair, and B. Koletzko, "Perinatal supply and metabolism of long-chain polyunsaturated fatty acids: importance for the early development of the nervous system," Annals of the New York Academy of Sciences, vol. 967, pp. 299-310, 2002. 
[63] K. R. Mahaffey, "Fish and shellfish as dietary sources of methylmercury and the $\omega-3$ fatty acids, eicosahexaenoic acid and docosahexaenoic acid: risks and benefits," Environmental Research, vol. 95, no. 3, pp. 414-428, 2004.

[64] P. M. Rodriguez, B. Koletzko, C. Kunz, and R. Jensen, "Nutritional and biochemical properties of human milk: II. Lipids, micronutrients, and bioactive factors," Clinics in Perinatology, vol. 26, no. 2, pp. 335-359, 1999.

[65] P. Xun, N. Hou, M. Daviglus et al., "Fish oil, selenium and mercury in relation to incidence of hypertension: a 20-year follow-up study," Journal of Internal Medicine, vol. 270, no. 2, pp. 175-186, 2011.

[66] S. Gamoh, M. Hashimoto, K. Sugioka et al., "Chronic administration of docosahexaenoic acid improves reference memory-related learning ability in young rats," Neuroscience, vol. 93, no. 1, pp. 237-241, 1999.

[67] M. Hashimoto, S. Hossain, T. Shimada et al., "Docosahexaenoic acid provides protection from impairment of learning ability in Alzheimer's disease model rats," Journal of Neurochemistry, vol. 81, no. 5, pp. 1084-1091, 2002.

[68] M. Hashimoto, Y. Tanabe, Y. Fujii, T. Kikuta, H. Shibata, and O. Shido, "Chronic administration of docosahexaenoic acid ameliorates the impairment of spatial cognition learning ability in amyloid $\beta$-infused rats," The Journal of Nutrition, vol. 135, no. 3, pp. 549-555, 2005.

[69] F. Leonardi, L. Attorri, B. R. Di et al., "Effect of arachidonic, eicosapentaenoic and docosahexaenoic acids on the oxidative status of C6 glioma cells," Free Radical Research, vol. 39, no. 8, pp. 865-874, 2005.

[70] P. Montuschi, P. J. Barnes, and L. J. Roberts, "Isoprostanes: markers and mediators of oxidative stress," The FASEB Journal, vol. 18, no. 15, pp. 1791-1800, 2004.

[71] W. S. Tsai, H. Nagawa, S. Kaizaki, T. Tsuruo, and T. Muto, "Inhibitory effects of n-3 polyunsaturated fatty acids on sigmoid colon cancer transformants," Journal of Gastroenterology, vol. 33, no. 2, pp. 206-212, 1998.

[72] R. Bera, T. K. Dhara, R. Bhadra, G. C. Majumder, and P. C. Sen, "Eicosapentaenoic and docosahexaenoic acids enriched polyunsaturated fatty acids from the coastal marine fish of Bay of Bengal and their therapeutic value," Indian Journal of Experimental Biology, vol. 48, no. 12, pp. 1194-1203, 2010.

[73] X. Jin, E. Lok, G. Bondy et al., "Modulating effects of dietary fats on methylmercury toxicity and distribution in rats," Toxicology, vol. 230, no. 1, pp. 22-44, 2007.

[74] A. Stokes-Riner, S. W. Thurston, G. J. Myers et al., "A longitudinal analysis of prenatal exposure to methylmercury and fatty acids in the Seychelles," Neurotoxicology and Teratology, vol. 33, no. 2, pp. 325-328, 2011.

[75] J. J. Day, M. N. Reed, and M. C. Newland, "Neuromotor deficits and mercury concentrations in rats exposed to methyl mercury and fish oil," Neurotoxicology and Teratology, vol. 27, no. 4, pp. 629-641, 2005.

[76] E. M. Paletz, J. J. Day, M. C. Craig-Schmidt, and M. C. Newland, "Spatial and visual discrimination reversals in adult and geriatric rats exposed during gestation to methylmercury and $n-3$ polyunsaturated fatty acids," NeuroToxicology, vol. 28, no. 4, pp. 707-719, 2007.

[77] P. Kaur, K. Schulz, M. Aschner, and T. Syversen, "Role of docosahexaenoic acid in modulating methylmercuryinduced neurotoxicity," Toxicological Sciences, vol. 100, no. 2, pp. 423-432, 2007.

[78] P. Kaur, I. Heggland, M. Aschner, and T. Syversen, "Docosahexaenoic acid may act as a neuroprotector for methylm- ercury-induced neurotoxicity in primary neural cell cultures," NeuroToxicology, vol. 29, no. 6, pp. 978-987, 2008.

[79] S. I. Grammatikos, P. V. Subbaiah, T. A. Victor, and W. M. Miller, " $n-3$ and $n-6$ fatty acid processing and growth effects in neoplastic and non-cancerous human mammary epithelial cell lines," British Journal of Cancer, vol. 70, no. 2, pp. 219227, 1994.

[80] USDA: US Department of Agriculture, Agricultural Research Service, USDA National Nutrient Database for Standard Reference-Release 18, Washington, DC, USA, 2005.

[81] World Health Organisation, Environmental Health Criteria 58: Selenium International Programme on Chemical Safety, World Health Organisation, Geneva, Switzerland, 1987.

[82] B. Akesson and T. S. Srikumar, "Occurrence of low-molecular-weight and high-molecular-weight selenium compounds in fish," Food Chemistry, vol. 51, no. 1, pp. 45-49, 1994.

[83] M. A. Quijano, P. Moreno, A. M. Gutierrez et al., "Selenium speciation in animal tissue after enzymatic digestion by highperformance liquid chromatography coupled to inductively coupled plasma mass spectrometry," Journal of Mass Spectrometry, vol. 35, no. 7, pp. 878-884, 2000.

[84] L. A. Daniels, "Selenium metabolism and bioavailability," Biological Trace Element Research, vol. 54, no. 3, pp. 185-199, 1996.

[85] B. Michalke and P. Schramel, "Selenium speciation in human milk with special respect to quality control," Biological Trace Element Research, vol. 59, no. 1-3, pp. 45-56, 1997.

[86] H. E. Ganther, C. Goudie, M. L. Sunde, M. J. Kopecky, and P. Wagner, "Selenium: relation to decreased toxicity of methylmercury added to diets containing tuna," Science, vol. 175, no. 26, pp. 1122-1124, 1972.

[87] J. H. Koeman, W. H. M. Peeters, and C. H. M. Koudstaal Hol, "Mercury selenium correlations in marine mammals," Nature, vol. 245, pp. 385-386, 1973.

[88] R. W. Chen, P. D. Whanger, and S. C. Fang, "Diversion of mercury binding in rat tissues by selenium: a possible mechanism of protection," Pharmacological Research Communications, vol. 6, no. 6, pp. 571-579, 1974.

[89] A. P. dos Santos, M. L. Mateus, C. M. Carvalho, and M. C. Batoreu, "Biomarkers of exposure and effect as indicators of the interference of selenomethionine on methylmercury toxicity," Toxicology Letters, vol. 169, no. 2, pp. 121-128, 2007.

[90] U. Lindh and E. Johansson, "Protective effects of selenium against mercury toxicity as studied in the rat liver and kidney by nuclear analytical techniques," Biological Trace Element Research, vol. 12, no. 1, pp. 109-120, 1987.

[91] V. C. Morris and O. A. Levander, "Selenium content of foods," The Journal of Nutrition, vol. 100, no. 12, pp. 13831388, 1970.

[92] J. Parizek and I. Ostadalova, "The protective effect of small amounts of selenite in sublimate intoxication," Experientia, vol. 23, no. 2, pp. 142-143, 1967.

[93] K. I. Folven, C. N. Glover, M. K. Malde, and A. K. Lundebye, "Does selenium modify neurobehavioural impacts of developmental methylmercury exposure in mice?" Environmental Toxicology and Pharmacology, vol. 28, no. 1, pp. 111-119, 2009.

[94] A. Fredriksson, A. T. Gardlund, K. Bergman et al., "Effects of maternal dietary supplementation with selenite on the postnatal development of rat offspring exposed to methyl mercury in utero," Pharmacology and Toxicology, vol. 72, no. 6, pp. 377-382, 1993. 
[95] N. Imura, "The role of micronutrient, selenium, in the manifestation of toxicity of heavy metals," Developments in Toxicology and Environmental Science, vol. 12, pp. 115-123, 1986.

[96] T. Nobunaga, H. Satoh, and T. Suzuki, "Effects of sodium selenite on methylmercury embryotoxicity and teratogenicity in mice," Toxicology and Applied Pharmacology, vol. 47, no. 1, pp. 79-88, 1979.

[97] H. Satoh, N. Yasuda, and S. Shimai, "Development of reflexes in neonatal mice prenatally exposed to methylmercury and selenite," Toxicology Letters, vol. 25, no. 2, pp. 199-203, 1985.

[98] N. V. C. Ralston, C. R. Ralston, J. L. Blackwell III, and L. J. Raymond, "Dietary and tissue selenium in relation to methylmercury toxicity," NeuroToxicology, vol. 29, no. 5, pp. 802-811, 2008.

[99] C. Watanabe, "Modification of mercury toxicity by selenium: practical importance?" Tohoku Journal of Experimental Medicine, vol. 196, no. 2, pp. 71-77, 2002.

[100] K. Julshamn, A. Andersen, O. Ringdal, and J. Morkore, "Trace elements intake in the Faroe Islands. I. Element levels in edible parts of pilot whales (Globicephalus meleanus)," Science of the Total Environment, vol. 65, pp. 53-62, 1987.

[101] J. Robinson and J. Shroff, "Observations on the levels of total mercury $(\mathrm{Hg})$ an selenium $(\mathrm{Se})$ in species common to the artisanal fisheries of Seychelles," Seychelles Medical and Dental Journal, vol. 7, pp. 56-60, 2004.

[102] M. F. Robinson, "The New Zealand selenium experience," American Journal of Clinical Nutrition, vol. 48, no. 3, pp. 521$534,1988$.

[103] A. L. Choi, E. Budtz-Jorgensen, P. J. Jorgensen et al., "Selenium as a potential protective factor against mercury developmental neurotoxicity," Environmental Research, vol. 107, no. 1, pp. 45-52, 2008.

[104] C. M. L. Carvalho, E. H. Chew, S. I. Hashemy, J. Lu, and A. Holmgren, "Inhibition of the human thioredoxin system: a molecular mechanism of mercury toxicity," The Journal of Biological Chemistry, vol. 283, no. 18, pp. 11913-11923, 2008.

[105] S. Jayashankar, C. N. Glover, K. I. Folven, T. Brattelid, C. Hogstrand, and A.-K. Lundebye, "Cerebral gene expression in response to single or combined gestational exposure to methylmercury and selenium through the maternal diet," Cell Biology and Toxicology, vol. 27, no. 3, pp. 181-197, 2011.

[106] N. V. C. Ralston and L. J. Raymond, "Dietary selenium's protective effects against methylmercury toxicity," Toxicology, vol. 278, no. 1, pp. 112-123, 2010.

[107] K. Seppanen, P. Soininen, J. T. Salonen, S. Lotjonen, and R. Laatikainen, "Does mercury promote lipid peroxidation? An in vitro study concerning mercury, copper, and iron in peroxidation of low-density lipoprotein," Biological Trace Element Research, vol. 101, no. 2, pp. 117-132, 2004.

[108] F. Usuki, A. Yamashita, and M. Fujimura, "Posttranscriptional defects of antioxidant selenoenzymes cause oxidative stress under methylmercury exposure," The Journal of Biological Chemistry, vol. 286, no. 8, pp. 6641-6649, 2011.

[109] R. F. Burk, "Selenium, an antioxidant nutrient," Nutrition in Clinical Care, vol. 5, no. 2, pp. 75-79, 2002.

[110] S. Bergmann, V. Neumeister, R. Siekmeier, C. Mix, U. Wahrburg, and W. Jaross, "Food supply abundant increase of serum selenium concentrations in middle-aged Dresden women between 1990 and 1996. DRECAN-team. Dresden cardiovascular risk and nutrition," Toxicology Letters, vol. 9697, pp. 181-187, 1998.

[111] L. Hagmar, M. Persson-Moschos, B. Akesson, and A. Shutz, "Plasma levels of selenium, selenoprotein $\mathrm{P}$ and glutathione peroxidase and their correlations to fish intake and serum levels of thyrotropin and thyroid hormones: a study on Latvian fish consumers," European Journal of Clinical Nutrition, vol. 52, no. 11, pp. 796-800, 1998.

[112] N. V. C. Ralston, J. L. Blackwell, and L. J. Raymond, "Importance of molar ratios in selenium-dependent protection against methylmercury toxicity," Biological Trace Element Research, vol. 119, no. 3, pp. 255-268, 2007.

[113] L. Flohe, "Glutathione peroxidase," Basic Life Sciences, vol. 49, pp. 663-668, 1988.

[114] P. Kaur, L. Evje, M. Aschner, and T. Syversen, "The in vitro effects of selenomethionine on methylmercury-induced neurotoxicity," Toxicology in Vitro, vol. 23, no. 3, pp. 378-385, 2009.

[115] S. Xiong, W. R. Markesbery, C. Shao, and M. A. Lovell, "Seleno-L-methionine protects against $\beta$-amyloid and iron/ hydrogen peroxide-mediated neuron death," Antioxidants and Redox Signaling, vol. 9, no. 4, pp. 457-467, 2007.

[116] L. Magos, M. Webb, and A. R. Hudson, "Complex formation between selenium and methylmercury," Chemico-Biological Interactions, vol. 28, no. 2-3, pp. 359-362, 1979.

[117] A. Naganuma, Y. Kojima, and N. Imura, "Interaction of methylmercury and selenium in mouse: formation and decomposition of bis (methylmercuric) selenide," Research Communications in Chemical Pathology and Pharmacology, vol. 30, no. 2, pp. 301-316, 1980.

[118] L. Magos and M. Webb, "The effect of selenium on the brain uptake of methylmercury," Archives of Toxicology, vol. 38, no. 3, pp. 201-207, 1977.

[119] K. Paulsson and K. Lundbergh, "The selenium method for treatment of lakes for elevated levels of mercury in fish," Science of the Total Environment, vol. 87-88, pp. 495-507, 1989.

[120] K. Seppanen, M. Kantola, R. Laatikainen et al., "Effect of supplementation with organic selenium on mercury status as measured by mercury in pubic hair," Journal of Trace Elements in Medicine and Biology, vol. 14, no. 2, pp. 84-87, 2000.

[121] B. R. Stillings, H. Lagally, P. Bauersfeld, and J. Soares, "Effect of cystine, selenium, and fish protein on the toxicity and metabolism of methylmercury in rats," Toxicology and Applied Pharmacology, vol. 30, no. 2, pp. 243-254, 1974.

[122] P. Frisk, A. Yaqob, K. Nilsson, and U. Lindh, "Selenite or selenomethionine interaction with methylmercury on uptake and toxicity showing a weak selenite protection: studies on cultured K-562 cells," Biological Trace Element Research, vol. 80, no. 3, pp. 251-268, 2001.

[123] M. Sakaue, T. Adachi, M. Okazaki et al., "Effects of sodium selenite on methylmercury-induced cell death and on mercury accumulation in rat cerebellar neurons in primary culture," Bulletin of Environmental Contamination and Toxicology, vol. 77, no. 5, pp. 779-784, 2006.

[124] Y. Yamane, H. Fukino, Y. Aida, and M. Imagawa, "Studies on the mechanism of protective effects of selenium against the toxicity of methylmercury," Chemical and Pharmaceutical Bulletin, vol. 25, no. 11, pp. 2831-2837, 1977.

[125] N. Ballatori, M. W. Lieberman, and W. Wang, "N-acetylcysteine as an antidote in methylmercury poisoning," Environmental Health Perspectives, vol. 106, no. 5, pp. 267-271, 1998.

[126] M. A. K. Khan and F. Wang, "Chemical demethylation of methylmercury by selenoamino acids," Chemical Research in Toxicology, vol. 23, no. 7, pp. 1202-1206, 2010.

[127] S. Passi, S. Cataudella, P. D. Marco, F. D. Simone, and L. Rastrelli, "Fatty acid composition and antioxidant levels in 
muscle tissue of different Mediterranean marine species of fish and shellfish," Journal of Agricultural and Food Chemistry, vol. 50, no. 25, pp. 7314-7322, 2002.

[128] E. N. Frankel, "Antioxidants," in Lipid Oxidation, E. N. Frankel, Ed., pp. 209-258, The Oily Press, Bridgwater, UK, 2005.

[129] P. Raspor, S. Plesnicar, Z. Gazdag et al., "Prevention of intracellular oxidation in yeast: the role of vitamin $\mathrm{E}$ analogue, Trolox (6-hydroxy-2,5,7,8-tetramethylkroman-2-carboxyl acid)," Cell Biology International, vol. 29, no. 1, pp. 57-63, 2005.

[130] V. F. Sagach, M. Scrosati, J. Fielding, G. Rossoni, C. Galli, and F. Visioli, "The water-soluble vitamin E analogue Trolox protects against ischaemia/reperfusion damage in vitro and ex vivo. A comparison with vitamin E," Pharmacological Research, vol. 45, no. 6, pp. 435-439, 2002.

[131] J. J. Garcia, E. Martinez-Ballarin, M. Robinson et al., "Protective effect of $\beta$-carbolines and other antioxidants on lipid peroxidation due to hydrogen peroxide in rat brain homogenates," Neuroscience Letters, vol. 294, no. 1, pp. 1-4, 2000.

[132] L. R. Barclay and M. R. Vinqvist, "Membrane peroxidation: inhibiting effects of water-soluble antioxidants on phospholipids of different charge types," Free Radical Biology and Medicine, vol. 16, no. 6, pp. 779-788, 1994.

[133] E. Cadenas, G. Merenyi, and J. Lind, "Pulse radiolysis study on the reactivity of Trolox $C$ phenoxyl radical with superoxide anion," FEBS Letters, vol. 253, no. 1-2, pp. 235-238, 1989.

[134] M. J. Davies, L. G. Forni, and R. L. Willson, "Vitamin E analogue Trolox C. E.s.r. and pulse-radiolysis studies of freeradical reactions," Biochemical Journal, vol. 255, no. 2, pp. 513-522, 1988.

[135] T. Doba, G. W. Burton, and K. U. Ingold, "Antioxidant and co-antioxidant activity of vitamin C. The effect of vitamin $\mathrm{C}$, either alone or in the presence of vitamin $\mathrm{E}$ or a water-soluble vitamin $\mathrm{E}$ analogue, upon the peroxidation of aqueous muitilamellar phospholipid liposomes," Biochimica et Biophysica Acta, vol. 835, no. 2, pp. 298-303, 1985.

[136] K. D. Massey and K. P. Burton, "Free radical damage in neonatal rat cardiac myocyte cultures: effects of $\alpha$ tocopherol, Trolox, and phytol," Free Radical Biology and Medicine, vol. 8, no. 5, pp. 449-458, 1990.

[137] T. W. Wu, N. Hashimoto, J. Wu et al., "The cytoprotective effect of Trolox demonstrated with three types of human cells," Biochemistry and Cell Biology, vol. 68, no. 10, pp. 11891194, 1990.

[138] H. Lee, K. Lee, J. K. Jung, J. Cho, and E. A. Theodorakis, "Synthesis and evaluation of 6-hydroxy-7-methoxy4-chromanone- and chroman-2-carboxamides as antioxidants," Bioorganic and Medicinal Chemistry Letters, vol. 15, no. 11, pp. 2745-2748, 2005.

[139] M. Sakaue, N. Mori, M. Okazaki et al., "Involvement of independent mechanism upon poly (ADP-ribose) polymerase (PARP) activation in methylmercury cytotoxicity in rat cerebellar granule cell culture," Journal of Neuroscience Research, vol. 86, no. 15, pp. 3427-3434, 2008.

[140] F. Usuki, A. Yasutake, F. Umehara et al., "In vivo protection of a water-soluble derivative of vitamin E, Trolox, against methylmercury-intoxication in the rat," Neuroscience Letters, vol. 304, no. 3, pp. 199-203, 2001.

[141] P. Kaur, L. Evje, M. Aschner, and T. Syversen, "The in vitro effects of Trolox on methylmercury-induced neurotoxicity," Toxicology, vol. 276, no. 1, pp. 73-78, 2010.
[142] S. Kato, K. Negishi, K. Mawatari, and C. H. Kuo, "A mechanism for glutamate toxicity in the C6 glioma cells involving inhibition of cystine uptake leading to glutathione depletion," Neuroscience, vol. 48, no. 4, pp. 903-914, 1992.

[143] T. H. Murphy, M. Miyamoto, A. Sastre, R. L. Schnaar, and J. T. Coyle, "Glutamate toxicity in a neuronal cell line involves inhibition of cystine transport leading to oxidative stress," Neuron, vol. 2, no. 6, pp. 1547-1558, 1989.

[144] L. C. Del Gobbo, J. A. Archbold, L. D. Vanderlinden, C. S. Eckley, M. L. Diamond, and M. Robson, "Risks and benefits of fish consumption for childbearing women," Canadian Journal of Dietetic Practice and Research, vol. 71, no. 1, pp. 41-45, 2010.

[145] M. C. Newland, E. M. Paletz, and M. N. Reed, "Methylmercury and nutrition: adult effects of fetal exposure in experimental models," NeuroToxicology, vol. 29, no. 5, pp. 783-801, 2008.

[146] C. D. Carrington and M. P. Bolger, "An exposure assessment for methylmercury from seafood for consumers in the United States," Risk Analysis, vol. 22, no. 4, pp. 689-699, 2002.

[147] JECFA, "Evaluation of certain food additives and contaminants. Twenty-second report of the joint FAO/WHO expert committee on food additives," Tech. Rep. 631, 1978, WHO Technical Report Series.

[148] National Institute for Environmental Health Sciences, Workshop organized by Committee on Environmental and Natural Resources (CENR), Office of Science and Technology Policy (OSTP), The White House: Scientific issues relevant to assessment of health effects from exposure to methylmercury, Raleigh, NC, USA, 1998.

[149] National Research Council, Toxicological Effects of Methyl Mercury. Board on Environment Studies and Toxicology, The National Academy Press, Washington, DC, USA, 2000.

[150] T. W. Clarkson, L. Magos, and G. J. Myers, "The toxicology of mercury-current exposures and clinical manifestations," The New England Journal of Medicine, vol. 349, no. 18, pp. 1731-1737, 2003.

[151] J. J. Strain, P. W. Davidson, M. P. Bonham et al., "Associations of maternal long-chain polyunsaturated fatty acids, methyl mercury, and infant development in the Seychelles child development nutrition study," NeuroToxicology, vol. 29, no. 5, pp. 776-782, 2008.

[152] G. J. Myers, P. W. Davidson, and J. J. Strain, "Nutrient and methyl mercury exposure from consuming fish," The Journal of Nutrition, vol. 137, no. 12, pp. 2805-2808, 2007.

[153] O. Sorg, B. Schilter, P. Honegger, and F. Monnet-Tschudi, "Increased vulnerability of neurones and glial cells to low concentrations of methylmercury in a prooxidant situation," Acta Neuropathologica, vol. 96, no. 6, pp. 621-627, 1998.

[154] H. M. Meltzer, M. Folmer, and S. Wang, "Supplementary selenium influences the response to fatty acid-induced oxidative stress in humans," Biological Trace Element Research, vol. 60, no. 1-2, pp. 51-68, 1997. 

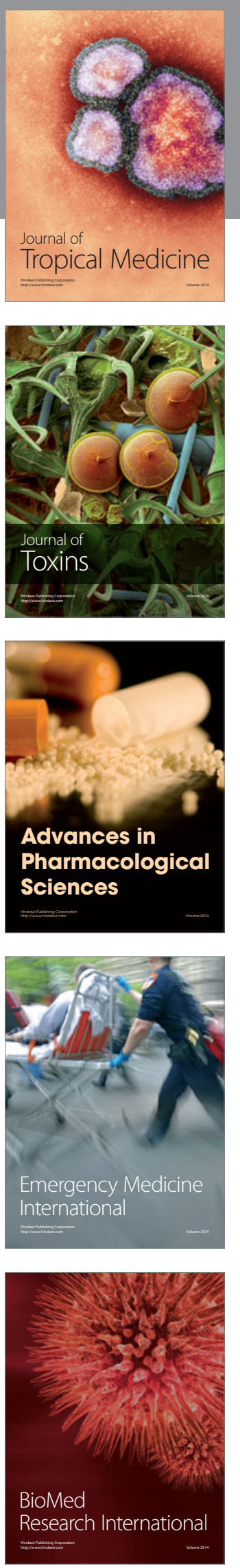
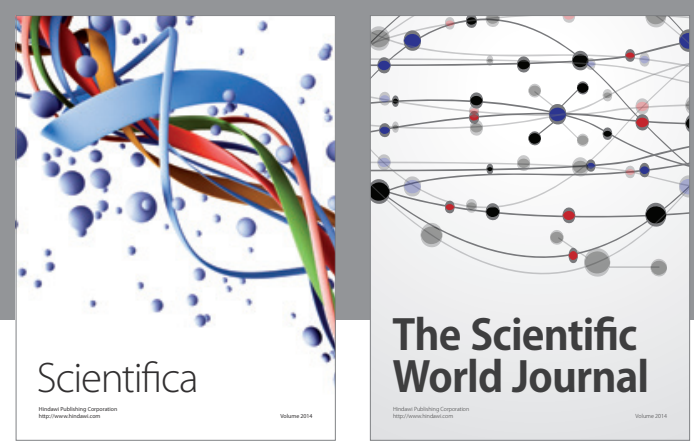

The Scientific World Journal
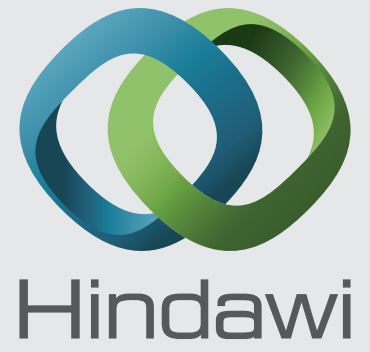

Submit your manuscripts at

http://www.hindawi.com
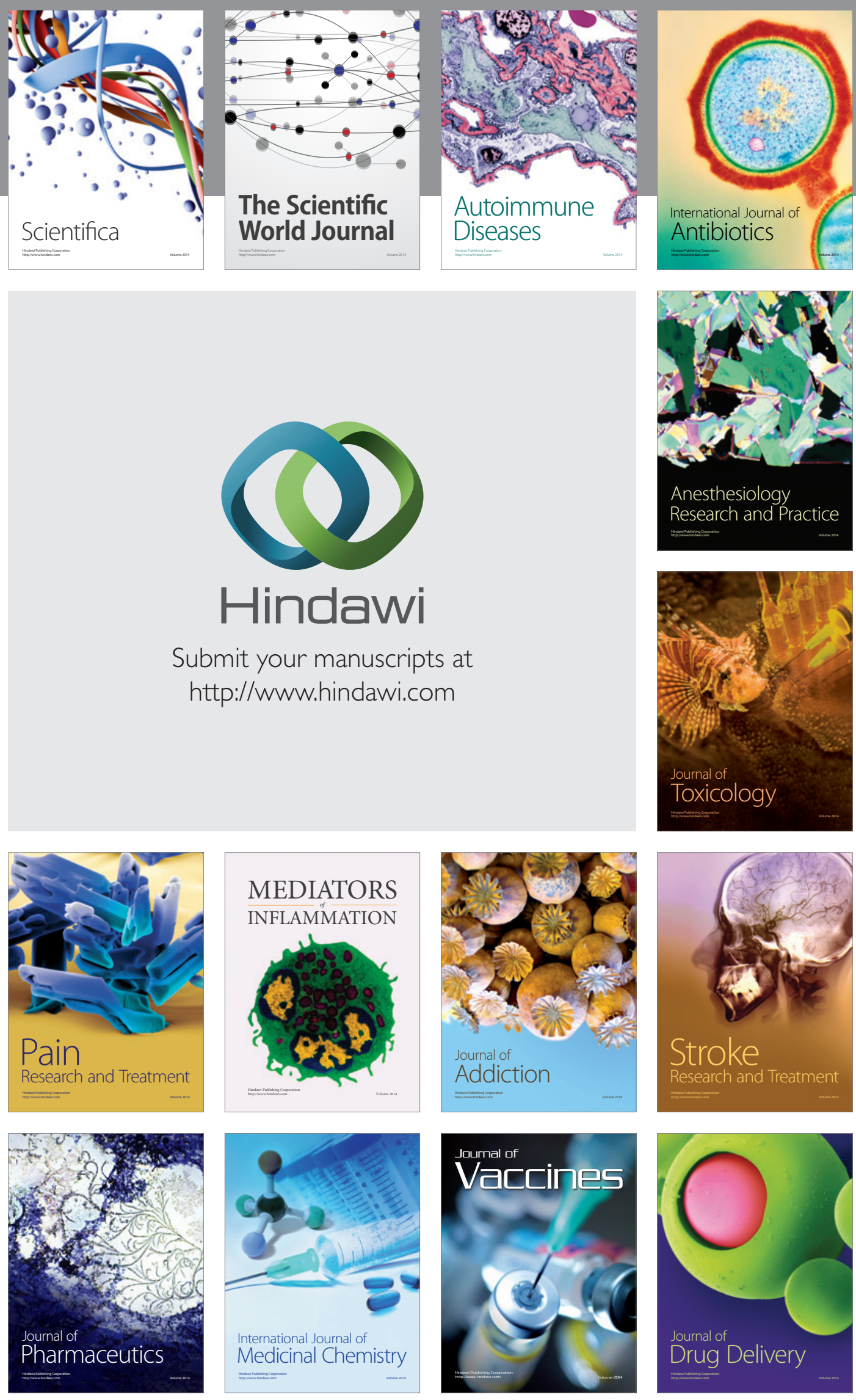